Comparative Philosophy Volume 2, No. 1 (2011): 38-60

Open Access / ISSN 2151-6014

www.comparativephilosophy.org

\title{
PLURALISM ABOUT TRUTH IN EARLY CHINESE PHILOSOPHY: A REFLECTION ON WANG CHONG'S APPROACH
}

\author{
ALEXUS MCLEOD
}

\begin{abstract}
The debate concerning truth in Classical Chinese philosophy has for the most part avoided the possibility that pluralist theories of truth were part of the classical philosophical framework. I argue that the Eastern Han philosopher Wang Chong (c. 25-100 $C E)$ can be profitably read as endorsing a kind of pluralism about truth grounded in the concept of shi 實, or "actuality". In my exploration of this view, I explain how it offers a different account of the truth of moral and non-moral statements, while still retaining the univocality of the concept of truth (that is, that the concept amounts to more than the expression of a disjunction of various truth properties), by connecting shi with normative and descriptive facts about how humans appraise statements. In addition to providing insight into pluralist views of truth in early China, the unique pluralist view implicit in Wang's work can help solve problems with contemporary pluralist theories of truth.
\end{abstract}

Keywords: Wang Chong, alethic pluralism, truth, Classical Chinese Philosophy, Han dynasty, truth in early China, metaphysics, actuality, shi-fei, shi-xu

There has been a great deal of discussion about whether early (pre-Buddhist) Chinese philosophers had a concept of truth. Much of this debate has been weighed down by the problematic assumption that the property expressed by the predicate 'is true', (or by any predicate in Chinese that roughly corresponds to the predicate in English 'is true') is something like correspondence between truth-apt propositions and "states-ofaffairs", and that any candidate concept in early Chinese philosophy for "truth" thus must express such a property. Generally, when scholars have shown a particular thinker or school within the Chinese tradition to be concerned with properties of sentences, names, teachings, propositions, or whatever bit of language is being considered, or when it is conceded that a particular thinker did have a conception of truth, they have taken him as primarily concerned with pragmatic properties of linguistic structures, such as "assertability" or usefulness for social harmony, etc., rather than correspondence properties, ${ }^{1}$ and have concluded that these thinkers were

MCLEOD, ALEXUS: Assistant Professor, Department of Philosophy, University of Dayton, USA. Email: mcleodaz@notes.udayton.edu 
either not interested in (or had no concept of) truth, or had a pragmatist conception of truth. $^{2}$

This assumption is false, and misses something important about the philosophy of language and metaphysics in the work of classical Chinese thinkers. The predicate 'is true' does not have to be understood as expressing a correspondence propertyindeed, the numerous debates within philosophy of language and metaphysics that rage today are over whether there is any property of truth at all, and if so what that property is. So it is far from obvious that any Chinese concept that can be understood as a concept of truth must be "truth as correspondence". To hold this would simply be to deny that coherentists, pragmatists about truth, or deflationists (who reject any metaphysical property associated with the predicate 'is true') are really talking about truth when they theorize about truth. Even if these philosophers are ultimately wrong about truth, it is wrong to say that they're not offering theories of truth. Likewise, in considering the early Chinese philosophers, we should be open to the possibility that they were operating with a conception of truth different from that of a correspondence theorist. Perhaps they were pragmatists, for example, and simply thought of the Chinese equivalents of 'is true' [such as ran (然), shi (是), you (有), shi (實), etc.] as expressing pragmatic properties.

I do not think, however, that this was the case. I believe it can be useful to see some of the early Chinese philosophers as pluralists about truth. That is, 'is true,' according to these thinkers, expresses different properties in different linguistic contexts. In some contexts the predicate 'is true' (然 ran, 實 shi, or whatever is playing the role of the truth predicate for the particular philosopher) might express the property of something like correspondence between sentences and states of affairs,

\footnotetext{
${ }^{1}$ That is, correspondence theory as an account of relations between propositions and states-of-affairs, not what we might call correspondence-truth in a folk theoretical sense, or what we might call the "correspondence intuition", that what is true must mirror in some sense the way things are.

${ }^{2}$ This is not true across the board, however. David Hall and Roger Ames argue in the above way (see Ames and Hall, 1998, Part 2), as does Chad Hansen, while Bryan Van Norden, for example, rejects this view. Van Norden's arguments are also problematic, however, as he seems to share the "truth as correspondence" assumption, and instead takes the tactic of denying that the early philosophers were primarily interested in pragmatic properties, but were indeed interested in something like correspondence. In specific, Van Norden claims that the early philosophers were concerned about truth because the predicate (specifically, ran) he identifies with 'is true' operates in the way dictated by Tarski's T-schema - that for any sentence $x$, ' $x$ ' is true iff $x$-where the single quoted use of $x$ is an occurrence in the object language and everything else is in the metalanguage. I believe that, unless the early philosophers were something like deflationists and thought there was nothing more to truth than this rule of the operation of the predicate ran, this cannot have been enough to define a concept of truth. The fact that they do, and Wang Chong certainly does, offer a more robust conception of truth than the simple semantic rule account, shows us that they had a different conception of truth than that of contemporary deflationists. Most importantly, the T-schema does not commit one to anything like correspondence (although proponents of deflationism might argue that it does account for the folk correspondence intuition). A truth predicate will obey the T-schema even if the truth predicate is robustly pragmatic, having nothing at all to do with the "way the world is." Thus the T-schema can't serve as a kind of "thin" conception of correspondence, or as a way to make sense of a folk conception of correspondence between statements and reality.
} 
and in other contexts ${ }^{3}$ 'is true' ${ }^{4}$ might express the property of assertability or usefulness to advance social harmony.

Below I argue that the Eastern Han dynasty philosopher Wang Chong's (c. 25$100 \mathrm{CE}$ ) conception of 實 shi in the Lun-Heng can be profitably and plausibly interpreted as a concept of truth unifying different properties in different linguistic contexts. The pluralist conception of truth arising from Wang's work differs significantly from contemporary pluralist theories of truth on a number of issues. The points of difference between these theories can be highly instructive in helping us understand the purpose and acceptability of pluralism about truth and the concept of truth in general, and as such can contribute to the contemporary debate about truth. I begin by discussing three different contemporary pluralist views of truth. In section 1, then continue to discuss the concept of shi and its evolution through early Chinese history in section 2. In section 3 I demonstrate the plausibility of reading Wang's Lun-Heng as offering a pluralist conception of truth which lends itself to a particular explication and development, and I show how such a pluralist theory can both inform the contemporary debate surrounding truth and pluralism and help us understand how early Chinese philosophers in general thought about truth.

\section{COMTEMPORARY THEORIES OF ALETHIC PLURALISM}

Pluralism about truth, or alethic pluralism, is relatively recent to the contemporary (post $20^{\text {th }}$ century) debate about truth, although it has predecessors throughout the history of western philosophy, and, I will argue below, in the history of Chinese philosophy (as well as the classical Indian tradition, where the Buddhist "two truths" view is an example ${ }^{5}$ ).

Contemporary pluralist theories of truth can generally be seen as a reaction to the perceived failure of "monist" theories of truth. Monist theories of truth generally take the concept of truth to express a particular single property belonging to certain linguistic entities-whether propositions, sentences, statements, or something else ${ }^{6}$.

\footnotetext{
${ }^{3}$ Or "discourses", or "domains". Philosophers discussing pluralist theories of truth have spoken in both ways. Michael Lynch speaks of "domains” (Lynch 2009), while Crispin Wright, (Wright 1992) speaks of "practices". Lynch says, in a statement of his functionalist pluralism: "For atomic propositions, ontologically distinct manifestations of truth are manifestations relative to a domain... a proposition is true because it has the further property that manifests truth for that domain." (Lynch 2009, p. 76)

${ }^{4}$ Or shi, ran, etc. - as I will argue below the variety of terms used to capture something like "truth" which are all functionally very similar are unified in Wang Chong's use of shi as a catch-all and something like an explanation of a functional concept operative in all linguistic contexts in which there can be truth-apt statements, teachings, etc.

5 The "two truths" view is that there are two levels of truth, relative truth and ultimate truth, and that some propositions or statements might be true in one sense but not the other, but that it is justified to call a statement meeting the normative objectives of one or other of these levels "true" (sat). For a good philosophical exposition of the "two truths" theory see Siderits 2003, ch. 8.

6 There has been debate over what kinds of entities are "truth-apt", which goes beyond the scope of this paper, and this debate connects closely to that over truth itself, as some views of truth-apt linguistic entities (such as propositions) are highly implausible as linguistic objects to certain philosophers and
} 
Monist theories of truth differ with respect to what they identify as this truth-making property. Contemporary monist theories have generally come in three loosely defined types:

correspondence theories, coherence theories, and pragmatic theories. ${ }^{7}$ All such theories are monist theories of truth, because they take truth to be a single property expressed by the concept of truth, such that anything which is truth-apt is so in terms of the possibility of having this single property. The only way things can be true is to have the single property the theory equates with the property of truth, for example, correspondence with states of affairs, coherence with beliefs or general worldview, etc. $^{8}$

Pluralist theories of truth are not necessarily in full disagreement with monist theories of truth on specific properties. One of the main features of pluralist theories is that they hold the predicate 'is true' expresses different properties in different domains or discourses (or however we define the relevant context). A pluralist might hold, then, that 'true' in discussions of physics or metaphysics, for example, expresses a property of correspondence, while 'true' in discussions of ethics or aesthetics expresses a property of coherence with other beliefs and one's general worldview.

One important feature of pluralist theories of truth is the notion of the requirements particular concepts must meet in order to be a concept of truth. Pluralist theories are in a difficult position in some sense. They offer ways to understand the concept of truth, and as such purport to be offering us an explanation of a single concept. The concept of truth itself is not plural - there is one concept of truth-on this much they agree with monist theories of truth. The key to pluralist theories is that the single concept of truth can express different properties in different domains or linguistic contexts, whereas monist theories hold that the single concept expresses one single property in all linguistic contexts in which there are truth-apt linguistic entities. The monist, however, has an easy way of defining the concept of truth-as the concept that expresses the particular property they identify with the truth property. The pluralist does not have this option. Although pluralist theories need to make

\footnotetext{
may constitute reasons against holding certain theories of truth (for example correspondence theories) insofar as these theories commit one to acceptance of these linguistic entities.

${ }^{7}$ These are all fairly loosely defined, of course, and theories within certain categories may radically differ from each other, while sharing some family resemblance to other theories of its kind. Perhaps the least well-defined of the categories of theory mentioned here is that of pragmatic theories of truth, which includes anti-realist theories of a variety of kinds.

${ }^{8}$ Another kind of theory of truth which will not be explicitly discussed here (mainly because none of the early Chinese philosophers held anything like this conception of truth) is the deflationary (sometimes also called disquotational) theory of truth, which denies that there is a robust property of truth at all, and understands truth as simply a tool for sentence evaluation that works in the way specified by Tarski's T-schema-for any sentence $x$, ' $x$ ' is true iff $x$-where the single quoted use of $x$ is an occurrence in the object language and everything else is in the metalanguage. That is, according to the deflationist, there is nothing more to truth than the syntactic rules for its use described by the Tschema (there are a number of different approaches to deflationist uses of the T-schema-see Gupta 1993), and looking for a robust property of truth belonging to linguistic entities is fruitless.
} 
sense of the univocality of truth, they cannot do so by defining the concept of truth as the concept expressing the truth property, because there are numerous truth properties, dependent on context. ${ }^{9}$ And it doesn't solve the problem to think of the concept of truth as expressing a disjunction of all the various properties in different domains or contexts the truth predicate expresses (such that ' $\mathrm{x}$ is true' iff $\mathrm{x}$ corresponds with states of affairs when $\mathrm{x}$ is a statement of physics, or $\mathrm{x}$ coheres with a general worldview when $\mathrm{x}$ is a statement of ethics... or...., etc). It is not, however, the disjunction that makes a statement of physics true, but the single property of correspondence. So with the disjunctive response there has been a failure to explain what it is about correspondence and about coherence (or whatever multiple properties of truth exist in the theory) have in common which make them truth properties. They certainly don't share the disjunction in common.

There are a few different ways one might answer the objection that pluralism theories cannot express truth as univocal. The different pluralist theories will turn on these answers. One way to make sense of the univocality of truth is to offer as a description of the concept of truth a set of platitudes about truth that any property must meet in order to count as a property of truth. In this way, we are able to have a univocal concept of truth, but one that will pick out a number of different properties in different domains or contexts, as different properties in these contexts will meet the requirements of the platitudes about truth. Crispin Wright famously takes this tactic, and offers a number of features of a truth property we might take to be platitudes about truth any property must meet to count as a truth property.

Wright proposes a list of platitudes as descriptive of the concept of truth (features that any property must meet in order to be a truth property), including "transparency""that to assert is to present as true", "opacity- that there are some truths we may never know or are incapable of coming to know", and "correspondence"- that for a proposition to be true it has to (in some sense) correspond to reality. ${ }^{10}$ The platitudes Wright mentions are negotiable - as we learn more about truth and how it works in different domains, we may find that some of the "platitudes" are unreasonable or otherwise wrong, and we may discover that there are other things that should be added to the list of platitudes.

Another way to capture the univocality of truth has been offered by Michael Lynch, who defines truth as a functional property. There is a particular property picked out by the predicate 'is true' across contexts, but this property can be realized

\footnotetext{
${ }^{9}$ Although a number of pluralist theories will attempt to identify the concept of truth with a single truth property in order to capture univocality, this single property for the pluralist will have to be connected in some way to other "truth" properties within specific contexts. For Lynch, the connection is based on the nature of the single truth property connected with the concept of truth as a functional property, such that different specific properties in different contexts can play the functional role of the truth property. For Mou, the connection is based on the specfication of the single truth property as the thinly specified property of non-linguistic truth, of "the way things are."

${ }_{10}$ (Wright 2001, p. 760). Wright offers seven platitudes here, and concedes after this "the list might be enlarged, and some of these principles may anyway seem controversial." He's not committed, that is, to exactly this list. Also see Wright 1992.
} 
by different robust properties in different contexts. This move avoids commitment to truth as a second-order property such as "the property of having a property that meets the truth platitudes," which Lynch sees as problematic, and I discuss in section 3.4 below. ${ }^{11}$

Bo Mou has offered a different way to understand a pluralist concept of truth. According to Mou, the general thesis that truth "captures the way things are" 12 can be represented in different ways in different "perspectives", through elaborations within given perspectives that are principles (fixed to perspective) expressing this basic thesis, such that the nature of truth itself is represented differently in different perspectives, while there is still a unified conception of truth underlying all of these perspective-based principles. ${ }^{13}$ In this way, Mou offers a pluralist that attempts to capture the univocality of the concept of truth through a single truth property whose plurality is accounted for by its different representation across perspectives.

I argue below that Wang Chong's conception of shi (實) as a tool for appraisal of teachings and linguistic entities offers us a detailed and explicitly pluralist theory of truth that operates differently from the three pluralist alternatives discussed above, although in certain key ways it is closest to Crispin Wright's view, as it does take the truth property to be a second-order property, but one based on basic facts about what humans do and should look for in statements, rather than on a list of platitudes concerning truth. While the view I will explain in the final section below may be thought of as simply a different way of specifying platitudes, it will turn out to be one that avoids some of the problems with Wright's view.

\footnotetext{
${ }^{11}$ Although in earlier work on truth as functional, Lynch accepted something like a higher order truth property, (see Lynch 2001), he has since modified his functionalist view such that it does not take truth as a higher order property. (Lynch 2009, p. 66: "truth can't be a second-order property...that would imply that truth is the property of having some property that has certain features. But does the secondorder property itself have those features?") He describes truth as manifested in certain contexts (or domains) in the following way: "Necessarily, $\mathrm{P}$ has the property that manifests truth for propositions of $\mathrm{D}$ if, and only if, it is a priori that, when had by atomic propositions of domain $\mathrm{D}$, the truish features are a proper subset of M's features," where ' $\mathrm{P}$ ' is a propositional variable, ' $\mathrm{D}$ ' is a domain variable, and ' $M$ ' is a variable ranging over possible manifesting properties, or realizers, of truth" (Lynch 2009, p. 77).

${ }^{12}$ (Mou 2009, p. 3). He has interestingly connected this to the concern with dao in early Chinese thought. In much of early Chinese philosophy, Mou claims, the basic truth thesis is understood in terms of capturing the dao, and different elaboration perspectives do this differently.

${ }^{13}$ Mou calls this basic thesis of truth the "axiomatic thesis of the nature of truth" (ATNT), and formulates it thus: "The nature of truth (of the truth bearer) consists in (the truth bearer's) capturing the way things are" (Mou 2009, p. 3). Interestingly, one of the things Mou atttempts to capture in his truth pluralism is the connection between not only truth in different linguistic contexts but also connection between linguistic and non-linguistic truth. Wang Chong, like other early Chinese philosophers, had a view of truth as a property of linguistic as well as non-linguistic entities. The issue of non-linguistic truth has been neglected, I believe, in much contemporary work on truth, and one of the advantages of looking to the early Chinese philosophers, as Mou does, is to understand how we might think of different types of truth.
} 


\section{SHI (實) IN ITS MEANING AS “REALITY” OR “ACTUALITY”}

The term shi (實) is used in many different senses in both Pre-Han and Han literature. This makes it especially difficult to isolate the use connecting shi (實) to truth, and in particular the pluralistic conception of the concept Wang Chong held.

The Eastern Han Shuo-Wen-Jie-Zi, compiled by Xu Shen, offers an etymology of shi. According to the Shuo-Wen, shi is defined as fu (富), or “fortune, wealth". It is broken into the mian (广) ("roof") radical and beneath it the character guan (貫), which is explained as coins (bei 貝) strung together on a thread. ${ }^{14}$ This shows us that $s h i$ is understood (according to Xu's etymology) as the wealth contained under one's roof-what one has stored away. We can see how this conception of shi leads to a conception of it as both something like "actuality" (or what is the real substance of a situation or person-we will see this conception play a large role in what is to follow), and "fullness". It is harder to see how we get from the Shuo-Wen's definition of shi to the sense of shi as "particular object" or the literal sense of "fruit" (we might wonder whether the literal sense of "fruit" could have been derived from seeing the fruit of a tree as the "fullness" or result of the full growth of the tree).

The specific sense of shi I am most interested in for purposes of this study is the sense of shi as something like "reality" or "actuality". Shi used in this way has a history itself. It evolved from the early uses in Pre-Qin texts ${ }^{15}$ to become something new in the Eastern Han thinkers, especially in the work of Wang Chong and later Xu Gan (170-217 CE). When we consider the use of shi as "actual properties" to evaluate sentences, as Wang often uses the term, we find that the most plausible interpretation of his use of shi in various linguistic contexts is as a theoretical basis for truth claims. If we examine the connection of the linguistic evaluative terms shi (是) and $f e i$ (非), as well as ran (然) and fou (否) to Wang's shi as “actual properties" (as I do in a section below), we begin to see the shape of a fairly robust theory of truth underlying his philosophical method and his discussion of language and the teachings of earlier philosophers.

This use of shi in the sense of "substantiality" or "actuality" is a major feature in a number of Pre-Qin and Han works on the relationship between 名 ming, ("name") and shi (實) ("actuality" or "reality"). Consideration of this issue can be found in the later Mohist and School of Names literature (especially in the Gongsunlongzi). It became a major issue in Eastern Han thought.

\footnotetext{
${ }^{14}$ It may help to mention that this is the same guan used in the famous (or infamous, depending on one's view of its true importance) "one strand" passage of the Analects, 4.15.

${ }^{15}$ There are uses of the term in the Analects, as "fullness" or "fruit" (Analects 8.5, 9.22), but the earliest philosophical use of the term in the Confucian texts is in the Mencius. Mencius 4B45, for example, reads 言無實不祥。不祥之實, 蔽賢者當之. (“Words without shi are not auspicious. Inauspicious shi conceal what the sages undertake.") Other examples of this use of shi occur at Mencius 4A27 and 7A37, and there is a consideration of ming-shi at 6B26.
} 
One of the features of this use of shi is its reference to linguistic entities, such as names, rather than physical objects, as in other uses of the term. ${ }^{16}$ The reason that this term becomes linked with consideration of names (ming 名) is that it is consideration of shi that is connected with the appropriateness of names. Wang, as I will show below, thinks of shi not as primarily connected with names, but rather with sentences. This is why the majority of his discussions of shi are connected with yan (言 "words", or "what is said") rather than ming-Wang is attempting to make clear that the contents of what is said in statements ${ }^{17}$ (or teachings) can be $s h i^{18}$

John Makeham considers the correlative thought of the early Han (especially that of Dong Zhongshu) to be a major source of the view of shi as justifying the application of names to things, locating there what he calls a "correlative theory of naming." 19 For Dong, it is the intentions of tian (天) which justify certain names, rather than shi (實) (which Makeham argues is an innovation of Xu Gan's). In Dong's work we see a movement toward correlative theories of naming based on the connection between tian and names. Names, on this view, gain their applicability or acceptability based on their correlation with (or, one might say, correspondence with) certain features of the world-in Dong's case, features of tian. ${ }^{20}$

I agree with Makeham that this is a major source of the transformation of the shi concept from that of something similar to "essence" or "substance" to a higher-order concept expressing actual properties of discussed entities (whether linguistic or otherwise). However, I do not think that Xu Gan was the first thinker to use shi as justificatory for naming (or the acceptability of sentences or other linguistic entities), or the basis for names. The earlier philosopher, Wang Chong, used shi as a way to evaluate linguistic entities whether (sometimes) names or (more often) sentences, teachings, and beliefs ${ }^{21}$. One of Wang Chong's innovations was to apply shi to a

\footnotetext{
${ }^{16}$ In much of the early literature, such as the Five Classics, shi is used with the sense of "fruit", as it is in the Analects, or as "full" or "solid particular object."

${ }^{17}$ Yan is not specific enough to allow us to consider whether by it Wang means something closer to "sentence", "proposition", "utterance", etc. It is unclear whether it refers to what is said or the content of what is said, or whether Wang takes there to be such a distinction at all. It sometimes appears to refer to what is said, sometimes to the content of what is said, but this is consistent with a number of different possibilities, including that Wang saw no difference between the two uses, or that he intended to express different senses of yan in different contexts. For this reason, I don't commit to a particular linguistic entity as expressed by yan, and use the term 'statement' which is comparatively neutral (although I realize that this term is fairly philosophically loaded as well).

${ }^{18}$ The distinction between yan and ming in the Lun-Heng is clear. Yan refers to a linguistic string rather than to an individual word, unless the individual word serves as a statement-for example, the word ke 可 ("acceptable") used as a response in the Gong-Sun-Long-Zi, can be an example of yan.

${ }^{19}$ Makeham 1994, ch. 5.

${ }^{20}$ specifically the 天意 tian yi, or "notions or intentions of heaven". Dong does use shi in connection with names in the Chun-Qiu-Fan-Lu, (in the Chu-Zhuang-Wang chapter, for example, he says 此聞其 名而不知其實者也 [“this is to be one who hears its name but does not know its shi”]), but his understanding of what shi represents seems to be based on its mirroring of tian.

${ }^{21}$ One feature, and some may think, weakness, of Wang's account, is that he did not consider there to be a single underlying structure of sentences, teachings, and beliefs which make these things truth apt.
} 
wider range of entities, including statements or teachings. It is the goal of what follows to show how Wang's shi operates with respect to statements, how this view of shi presents us with a pluralist theory of truth, ${ }^{22}$ and then consider how this kind of pluralism can both help us in the contemporary debate and in our understanding of ancient Chinese philosophy.

\section{SHI IN THE LUN-HENG—A THEORY OF ALETHIC PLURALISM}

\subsection{SHI AS NORMATIVELY POSITIVE PROPERTY}

Two essays in particular in the Lun-Heng offer us the greatest insight on Wang's view of shi as a pluralist concept of truth. The Dui-Zuo 對作 (“Defending Creations"), and the Wen-Kong 問孔 ("questioning Confucius") chapters show us how Wang uses shi to appraise teachings and sayings (言 yan).

The Dui-Zuo chapter shows us shi (實) connected with the oppositions shi (是)/fei (非) and ran (然) (“what is the case”)/fou (否) (“what is not the case”). Shi (實) is contrasted with $x u$ (虛) (“falsity”, “merely apparent properties”, “empty [talk]”). ${ }^{23}$

The main purpose of the Dui-Zuo chapter is twofold: One purpose is to demonstrate that corrections $d u i$ 對 are needed to the classic texts (everything which has come before him) and to contemporary writings and teachings based on "unfounded or empty assertions" (虛言 $x u$ yan). Wang does something similar in the beginning of the 問孔 Wen-Kong chapter. There he offers reasons for the "criticisms" of Confucius he goes on to deliver, along with a method for appraising teachings or

One of the features of contemporary analytic philosophy of language is that it has generally made a distinction between beliefs and teachings and what makes these things truth evaluable - most often sentences or propositions (depending on one's semantic theory). Beliefs and teachings then are truth apt insofar as they express propositions or sentences, which can be truth apt. My belief itself cannot be true, but the sentence or proposition I accept in the act of belief can be true or false, and it is in this sense that the belief is said to be true or false, connected to the contents of belief. There are a couple of reasons we generally think this needs to be done (a) teachings and beliefs, we think, are not linguistic entities, and thus cannot themselves be semantically evaluated, (b) in desiring or requiring truth to be unitary, insofar as we think there ought to be a single property of truth, we cannot make sense of two different types of entity, propositions or sentences as linguistic entities, and beliefs as mental entities or something like this, as having the same property (of truth), because we cannot explain how a single property could belong to things of seemingly vastly different types. If one is a certain kind of pluralist about truth, however (note that not all pluralists will find this acceptable), one can make sense of these different types of entities being truth evaluable.

${ }^{22}$ I do not argue here that Wang Chong held a pluralist view very much like the worked out views of contemporary philosophers such as Lynch and Wright, but rather that his view of 實 shi is a kind of pluralism that gets its start from the same intuitions and is spelled out in a similar way to contemporary pluralist theories, in that multiple properties across domains or discourses can meet the concept of truth, and thus things can be true in different ways or senses.

${ }^{23}$ Wang's $x u$ is a much more complicated concept than even this jumble of translations suggests, and is perhaps more different from our concept of "falsehood" than shi is from "truth". I will discuss $x u$ in more detail below. 
statements in general (which he discusses and uses in the Dui-Zuo chapter as well). Wang's other purpose in this chapter is to defend his own work insofar as it is a “creation" (作 zuo) rather than a "relation" or “tradition" (zhuan 專 or shu 術), and the usefulness of "creations" in general. ${ }^{24}$ The dominant view of the day, as Wang recounts in the chapter, is that only the sages were justified in creating (zuo) and that those who are merely worthies should concentrate on transmitting $(s h u)$ the creations of the sages. ${ }^{25}$ Wang here attempts to defend the usefulness of innovation by less than sagely people such as himself. Wang is basically defending himself for his "innovations" here, arguing that "creations" such as the Lun-Heng have become necessary because corrections are needed to the traditions, which have perpetuated falsehoods and exaggerations.

In the Dui-Zuo chapter, because it is both a defense of Wang's work and an explanation of the efficacy of "corrections" ( $d u i$ 對), there is some consideration of the concept of shi (實) and the related concepts of shi-fei (是非) and ran-fou (然否). In the early part of the chapter, Wang discusses shi (實) and explains how certain writings were historically necessary, due to the failure of the common people to recognize the truth:

眾事不失實, 凡論不懷亂, 則桓譚之論不起。If the multitude in their works had not gone astray from truth (shi), and some discussions had not gone bad and become disordered, then Huan Tan would not have written his works (LH 84.362.15-16). ${ }^{26}$

It is for similar reasons that Wang Chong wrote the Lun-Heng. As he explains near the end of the chapter:

論衡九“虛”, 三“增”, 所以使務實誠也。In the Lun-Heng the nine chapters on "falsity" and three chapters on "exaggerations" are meant to create in people the impetus to strive for truth (實 shi) and sincerity (誠 cheng) (LH 84.364.22).

\footnotetext{
${ }^{24}$ There were a number of different views on the value of creation zuo in the Pre-Qin and Han periods. Wang here is reacting against a particularly conservative strain of Confucianism in the Han which took the claim of the Analects quite literally (in Analects 7.1 Confucius says “transmit, and don't create" 述 而不作), that what scholars should be engaged in is transmitting (shu 述) rather than creating, and that even the sages did not create new things. An alternative view held by some is that only the sages can and are justified in creating (zuo), and that lesser persons, mere worthies such as Wang Chong cannot and should not attempt to create. Michael Puett explores the different attitudes on zuo before Wang's time in Puett 2001.

${ }^{25}$ A view advanced by a number of Pre-Qin and Han authors, according to Puett.

${ }^{26}$ All passages from the Lun-Heng follow the chapter, page, and line numbering in the Lun-Heng-ZhuZi-Suo-Yin 《論衡逐字索引》[Critical Essay: Concordance], Chinese University of Hong Kong Institute of Chinese Studies, Ancient Text Concordance Series, No. 22 (Hong Kong: The Commercial Press, 1996). Citation is chapter, page, line(s). All translations from the Lun-Heng are my own, unless otherwise noted.
} 
We see here that the critical problem Wang is trying to address is the ignorance of $s h i$ he thinks is endemic in his society and in the writings of contemporary scholars.

\section{2. $X U$ AS ATTRACTIVE AND "MERELY APPARENT" PROPERTIES}

Shi is opposed with $x u$ (虛), which is translated often as "emptiness" or "falsity". The sense of $x u$ as "false" grows out of its meaning as "empty", and in Wang's writings it is has the sense of "merely apparent qualities." This way of understanding $x u$ helps us to make sense of passages in which Wang talks as if $x u$ words or teachings qua $x u$ words and teachings are naturally attractive. Understanding $x u$ as "falsity" does not give us an explanation of the attractiveness of $x u$ things, according to Wang. Statements that are simply false do not necessarily attract us, unless they have some other attractive features - such as making us feel better about ourselves, etc. It is not the falsity of certain propositions that leads us to assent to, believe in, live by, or otherwise adopt them, but rather some other attractive feature. With the concept $x u$, however, there does seem to be a built in attractiveness $x u$ entities possess qua $x u$ entities.

Wang mentions the seemingly attractive features of $x u$ entities in the Dui-Zuo chapter, in his discussion of shi (實). He says of the "common people"27:

俗之性, 好奇怪之語, 說虛妄之文。何則? 實不能快意, 而華虛驚耳動心也。是故 才能之士, 好談論者, 增益實事。It is the nature of common people to enjoy strange stories and sayings, to delight in empty ( $x u$ 虛) and absurd writings. Why is this? The truth (shi 實) isn't easily [or quickly] believed, but flowery and empty speech astounds the hearers and excites their minds. This is why scholars with talent, who enjoy discussion, add things to and exaggerate the truth (shi 實) about affairs (LH 84.362.26363.1).

$X u$ statements are (or at least can be) flowery, ornate, and naturally appealing to the "common people" (with the intimation that those of high talent will not find $x u$ statements compelling). There seems to be a necessary link between $x u$ and flowery statements, as the "floweriness" of $x u$ statements serves as the reason that the common people tend to accept such statements. At first reading, it seems that Wang has failed to consider two possibilities: that there might be (1) true statements that are flowery; and (2) false or empty statements that are not flowery and appealing. But if we take Wang to be claiming that there is something inherent in $x u$ statements that makes them appealing, we can show he is not making this (seemingly elementary) mistake. $X u$ statements are appealing partly because they appear to be true, even when "appearance" is thought of in terms of tendency to accept (something we easily accept may be thought to, in this way, appear to us as true). Does this mean then that Wang thinks of shi statements as appearing false, and thus being rejected by the "common people?" If we take "appearing" true as linked to appeal to imagination, or

${ }^{27}$ or, “simple people" (俗人 su ren). 
being “easily (or quickly) believed" (kuai yi 快意), then the fact that the truth is not quickly or easily believed, or is unappealing to the "common" does show that it, in a sense, does not appear true. Of course, it will appear true to those above the common, who possess some wisdom, and it is thus the responsibility of such people to write works promoting the truth, to stir up energy in the common people to seek the truth. And it can come to appear true to the common people given proper instruction by more wise people (such as Wang Chong and others he praises).

Does something appear to be true simply because someone asserts it, for example? Think of a statement like "Confucius was 10 feet tall." To assert this (in a serious way, outside contexts of joking, fiction, or semantic ascent) is to assert it as true, even though it is in fact false (one might be lying, ignorant, or misinformed). In most normal contexts, a sentence such as this would be uttered so as to inform or convince another person of certain features of Confucius, namely that he was 10 feet tall. Assertion of $x$ is to present $x$ as true. It would be naïve, we might think, to take assertion as grounds for belief, but if we consider the normal case, this is often what we in fact do. We generally take a friend's assertion that "it is 11:30 am" or "Bill isn't here yet" or "Bill has grey hair" as acceptable grounds for assenting to the statement asserted. At more removed levels, we accept the assertions of experts of all kinds when they say things like "smoking causes cancer," or "Jupiter's upper atmosphere is 90 percent hydrogen." The mistake common people (俗人 su ren) often make, according to Wang, is failure to be reflective. They accept what is asserted by people around them as true, even though these people are often either ignorant, misinformed, or dishonest.

$X u$ statements, then, can be thought of as false statements that we are somehow inclined to believe. So why are we inclined to believe them? Is it due to the mere fact of their being asserted (in the right context)? Or is there some more robust explanation? The above seems to suggest that there is something extra that $x u$ statements have.

$X u$ statements are not only ones we would be inclined to believe due to assertion, but they have some other compelling quality - common people delight in them and they appeal to the imagination. Thus, common people are more likely to imagine these statements as possessing the properties that would make them shi, based on wishful thinking. We can see how this might work. Human psychology is such that it is far easier to get someone to believe something they would like to be true than something they either have no interest in or do not want to be true. This facet of our psychology can be and has been used to great effect by those wishing to deceive in various ways. ${ }^{28}$ But how about in cases of ignorance or misinformation? The

\footnotetext{
${ }^{28}$ What I mention here is similar to some forms of cognitive bias, such as wishful thinking and confirmation bias. There are many other forms of cognitive bias as well, which shows how prone humans are in general to accept false statements as true even in the face of overwhelming evidence of their falsity. This is very much Wang's worry. In fact many of the problems with the beliefs of su ren he mentions in the Lun-Heng line up with a number of cognitive biases contemporary behavioral psychologists discuss. He most vehemently heaps scorn upon wishful thinking, which he isolates as a particularly pressing problem among common people in his time.
} 
statement "Bill is 6 feet tall" may be false, and I may believe and thus assert this statement, to inform a friend about features of Bill. I may have been misinformed, however, having never met Bill. In fact, say, Bill is only 5 feet 7 inches tall. There is nothing intrinsically compelling, beyond my assertion, about the statement "Bill is 6 feet tall." This is not something we would expect to "appeal to the imagination" or be believed due to a human inclination to accept the fantastic. Rather, it will generally be accepted because I assert it and the listener has no reason to doubt that what I say in such cases is true. So is this statement $x u$ ?

For Wang, statements of this kind are not $x u$. There are statements, like my example of "Bill is 6 feet tall," that are not-shi but are also not-xu. The reason Wang does not speak about this kind of statement is that he is mainly concerned with $x u$ statements as compelling to su ren. Xu statements are most problematic. We can and do easily correct our mistakes when they involve things that we have no general inclination to accept. My friend might believe me that Bill is 6 feet tall, but when he gets different information from someone else, he will likely come to doubt what I told him, and remain agnostic about Bill's height until meeting him. However, $x u$ statements are much trickier than this because cognitive bias is involved. We are hesitant to give up belief in statements we would like to be true, for example, and often hold to them even in the face of overwhelming evidence that they are false.

Shi 實, as the opposite of $x u$, is being used to flag actual properties (the actual possession of the properties we seek when appraising statements) as opposed to merely apparent properties (the mere apparent possession of these properties) of statements, teachings, or whatever can be shi-apt. To see what these properties are, we have to look to Wang's discussion surrounding concepts related to shi and $x u$.

\subsection{MORAL NORMATIVITY}

In the Dui-Zuo chapter there are two dichotomies discussed in relation with shi and $x u$-namely shi-fei (是非) and ran-fou (然否). In the Dui-Zuo chapter, shi (是) and $f e i$ (非) when discussed as concepts rather than verbally used, seem to be connected to ethical or normative contexts. Alfred Forke, in his translation, noticed this and translated shi (是) and fei (非) in the Dui-Zuo chapter as "right" and "wrong" respectively, in all the places where they are discussed as evaluative properties. We see shi and fei mentioned along with ran and fou, "is the case" and "is not the case" in discussions of shi (實) in the chapter. Two passages in particular show us the two dichotomies discussed together:

明讋然否, 病心傷之, 安能不論? ... 〔孟子]引平直說, 褒是抑非。

Those who can determine what is the case and what is not the case feel an ailment in their hearts which pain them [at the thought of truth being subverted by the "common people" and flowery scholarship] ... [Mencius'] language was straight 
and to the point, according high place to the right (是 shi) and suppressing the wrong (非fei) (LH 84.363.3-5). ${ }^{29}$

One may find it curious that shi and fei are translated here as "right" and "wrong", which suggest moral normativity, while ran and fou are translated in more clearly truth-evaluative terms as "what is the case" and "what is not the case". What is the justification for the difference? Are we given any reason to read shi and fei as I do in the above passage? A consideration of some other instances of shi and fei in this chapter may help. The following passage is crucial for understanding the normative use, as well as for understanding how Wang may be seen as a pluralist about truth.

況論衡細說微論, 解釋世俗之疑, 讋照是非之理, 使後進曉見然否之分。The LunHeng uses precise language and detailed discussion, to reveal and explain the doubts of this generation of common people, to bring to light through debate right and wrong principles (是非之理 shi fei zhi li), and to help those who come later clearly see the difference between what is the case and what is not the case (LH 84.364.10-11). ${ }^{30}$

Here, we see shi and fei connected to the "principles" ( $l i$ 理) Wang aims to uncover. His purpose in the Lun-Heng is to reveal shi and fei principles and to help people distinguish between what is the case and what is not the case. What is the reason for using of two different formulations here, shi-fei and ran-fou, if he means something like "truth and falsity" in both cases? It is implausible that this should be seen as simply using synonyms to mean something like "truth and falsity", so that he is saying that he wants to (1) uncover true and false principles, and (2) help people distinguish between what is true and false. This point is strengthened by his use of $l i$ (理), by which Wang means something like "moral principle." This is far from the Song Neo-Confucian use of $l i$ (理) to express a foundational metaphysical concept. The above mentioned is the only occurrence of $l i$ in the Dui-Zuo chapter, but if we look to the Wen-Kong ("Questioning Confucius") chapter, in which consideration of argument and method is a central theme ${ }^{31}$, we learn more about how Wang uses $l i$.

難孔子，何傷於義？誠有傳聖業之知，伐孔子之說，何逆於理？... [if we] challenge Confucius, how is this injurious to moral appropriateness? If, sincerely

\footnotetext{
${ }^{29}$ It is useful here to consider Forke's translation as well, which, like my own, uses "right" and “wrong” for 是 shi and 非 fei: “He who knows how to discriminate between truth (ran) and falsehood (fou), must feel a pang at it; why should he not speak? ... [Mencius] used plain and straightforward language to recommend what was right, and to reject what was wrong."

${ }^{30}$ Forke reads the shi in the final part of this passage as causally connected to bringing light to right and wrong principle - he translates: “... intended to explain the right and wrong principles so that future generations can clearly see the difference between truth and falsehood." (Forke 1907, p. 88)

${ }^{31}$ This is somewhat contentious. Michael Nylan argues (Nylan 1996) that Wang's purpose in the WenKong chapter was to show Confucius an ultimately unsuccessful teacher, while I argue (McLeod 2007) that Wang's purpose in Wen-Kong was primarily methodological rather than critical.
} 
attempting to transmit the knowledge of the sages' teachings, one attacks Confucius' words, how does this oppose principle (li)? (LH 28.122.7)

This is clearly a view of $l i$ as either the collection of moral norms or the ground of moral norms. Wang's second sentence is explaining his first. Challenging (難 nan) Confucius is not injurious to moral appropriateness (義 $y i$ ), because attacking Confucius' words in order to clear things up does not violate the correct moral principles that make certain acts appropriate or inappropriate. This is also argued in another passage in the Wen-Kong chapter, ${ }^{32}$ in which Wang criticizes Confucius for violating $l i$ by picking on the weaknesses of Meng Yizi and thus acting "contrary to the will of the Duke of Zhou” (違周公之志).

If we take these uses of $l i$ to be the same as that in the above passage from the Dui-Zuo chapter, then it looks like the passage gives us two separate goals of the LunHeng - a moral goal, uncovering true moral principles, and a non-moral goal, of determining what is the case and what is not the case. Now, the question becomes, why distinguish the two? Wouldn't simply "discovering the truth" take care of both of these? Why didn't Wang simply say that the purpose of the Lun-Heng is to uncover the truth, to help us distinguish between shi 實 and $x u$ 虛, which seems his main purpose as he describes it in other passages? If he is after truth, after all, then it looks like facts about moral principles and what is the case will just fall out of this pursuit. If we know what is true, then by definition we will know which moral principles, if any, are right, because we will know whether normative statements, such as "one should never pick on the weaknesses of another," are true.

There seems to be some connection between fou-ran and shi-fei in LH 84.363.3-5 above, where Wang talks about Mencius' ability and action. According to this passage, those who have the ability to discriminate between what is the case and what is not the case (ran and fou) are able to use language to point out what is right (是 shi) and what is wrong (非 fei). So knowledge of moral principle does seem to follow from ability to discriminate between what is and what is not the case. Does this, however, show us that there is a single property of truth, such as ran (what is the case) operative in all contexts? A consideration of shi (實) shows us that it is the wise person's grasp of shi (實) that enables him to both distinguish between what is and what is not the case and to distinguish between right and wrong moral principles. It is not, that is, ability to distinguish between ran and fou which makes one able to distinguish between $s h i$ and $f e i$, but rather the ability to distinguish between shi (實) and $x u$ (虛) which makes one able to make both of the other types of discrimination. The fact that Mencius had the ability to distinguish between ran and fou showed that he had the ability on which the ability to distinguish between shi (是) and fei (非) rests.

The ability to distinguish between 實 $s h i$ and 虛 $x u$ then presumes the ability to make a number of other useful discriminations involving teachings, statements, and

${ }^{32}$ LH 28.123 .1 
other entities. Shi and $x u$, that is, seem like higher-order concepts, unlike ran and fou or shi and fei. I believe the best way to make sense of this is to take 是 shi and 然 ran as ways in which something can be 實 shi (“actual", "true"), while 非 fei and 否 fou are ways in which something can be 虛 $x u$ (“empty", “false", “only apparently true"). That is, Wang is offering a view of 實 shi in which what makes a statement (言 yan) 實 $s h i$ is either being 是 $s h i$, or being 然 ran.

A moral principle, such as mentioned in the above case: “don't attack people's weaknesses" can be 是 shi or 非 $f e i$, but we can clearly see (we would share Wang's intuition) that phrased in this way, it cannot be "the case" or "not the case", because it is not an assertion about a state of affairs. We could reformulate this so it would look like an assertion about a state of affairs, and render it this way: "one should not attack people's weaknesses." This formulation seems "is the case"-apt, as it is formulated in such a way as to suggest the possibility of a state-of-affairs that makes it the case that one should (or should not) attack people's weaknesses, whether we understand this state-of-affairs to involve moral facts (whatever these are), teleological features of humans, or anything else that could belong to a state-of-affairs of the world and also explain the normativity involved in this principle.

Wang, however, does not evaluate moral principles in this way, in terms of statesof-affairs. He considers statements like "don't attack people's weaknesses" and their acceptability in terms of 是 shi and 非 fei, “right" and “wrong". If normativity in moral cases is basic on Wang's view, and not based on facts about "what is the case", we can explain easily why Wang distinguished 實 shi-making properties for moral statements from 實 shi-making properties for non-moral statements. There are simply different properties which make these different kinds of statements or teachings 實 shi (true, actual). And if this is the case, then Wang can be seen as a pluralist about 實 shi, in a way similar to contemporary alethic pluralist theorists about "truth". 33

\footnotetext{
${ }^{33}$ Special thanks are due to a reviewer of this article who correctly points out that the evidence I have offered here is not by itself conclusive to show that Wang held a pluralist theory of truth, especially one using the terminology and concepts of contemporary analytic philosophy. Although Wang perhaps did not explicitly have a pluralist view like the one I sketch below, I think this theory is the best way to make sense of what Wang says in the Lun-Heng concerning shi, as it makes his position strongest, even though what he says is also compatible with a number of other interpretations, including the possibility that the differences between evaluative terms in different contexts were merely stylistic. Although I import the conceptual apparatus of contemporary analytic philosophy to reconstruct Wang's view of truth, I realize that this distorts Wang's view to the extent that Wang did not work with such a conceptual apparatus. Much of what follows below is my attempt to reconstruct Wang's basic view of truth and extend it using the tools available to contemporary philosophy. Thus, much of what follows is not explicitly held by Wang, but rather is a natural way of developing his pluralist view of truth. As such, it can be seen as continuous with Wang's theory of truth, even if it is less useful for understanding the way early Chinese thinkers theorized about truth (although the general pluralism I attribute to Wang above can, I think, be useful for this latter project as well).
} 


\title{
3.4. UNIVOCALITY AND THE USEFULNESS OF WANG'S THEORY OF TRUTH
}

Which properties then are expressed by 實 shi? Moral acceptability (是 shi) is one property expressed by 實 shi, in the moral domain. This property of acceptability would not, however, make non-moral statements about physical objects true. This property can only be a shi-making property in the appropriate domain. Non-moral statements cannot be 是 $s h i$, just as moral principles cannot be 然 $\mathrm{ran}^{34}$

At least one difficult problem remains, however. One key feature of the concept of truth, or the concept of 實 shi, is that it should be a univocal concept. Even though there might be different properties in different linguistic contexts that make a statement true, it can not be the case that "truth" (or 實 shi) means different things in different contexts. It should mean the same thing to say that a moral statement is true as it does to say that a non-moral statement is true. As I've shown in the previous section, one way of capturing this is to define the concept of truth by way of a number of platitudes that any property in any relevant domain must meet in order to be a truth property. Thus, the meaning of 'truth' can be understood in terms of the platitudes, while the properties the concept expresses are variable in different contexts. Wang Chong, however, does not seem aware of either this problem of univocality or the conception of fixing the meaning of truth via platitudes. Shouldn't this lead us to question whether Wang actually did have a pluralist view of truth?

I think that the question of how to account for the univocality of shi did not arise for Wang due to his conception of what the property of 實 shi is, and how it relates to the “truthmaking” properties 是 shi and 然 ran. On Wang's view of 實 shi, there is no difficulty in accounting for univocality, because the concept of shi is of a unified second-order property linked to particular truthmaking properties that differ by context.

We find passages in the Lun-Heng that show us that Wang did think of shi as univocal. The following passage from the Dui-Zuo chapter is informative here:

\begin{abstract}
人君遭弊, 改教於上; 君臣（愚）惑, 作論於下。〔下〕實得, 則上教從矣。冀 悟迷惑之心, 使知虛實之分。實虛之分定, 而華僞之文滅; 華僞之文滅, 則純誠之 化日以杽矣。When the ruler does badly, instruction to change conduct is directed toward the person on high. When the ruler's subjects are doltish, engaging in discussions is directed toward the people below. When the people below obtain the truth (實 shi), then instruction of the person on high follows. I hope to stir some of these minds, to help them distinguish between truth (實 shi) and falsity (虛 $x u$ ). Once the distinction between truth and falsity is established, then flowery and artificial writings can be eliminated. When flowery and artificial writings are eliminated, pure and sincere transformations will grow more abundant day by day (LH 84.363.12-14).
\end{abstract}

\footnotetext{
${ }^{34}$ This seems to mesh with our own intuitions if we consider sentences like "don't attack people's weaknesses." It seems to make no sense to say that this can be the case or not be the case, whether or not a reformulation as described above will give us a sentence that can be the case or not be the case.
} 
In this passage, we see that the ability to distinguish between shi and $x u$ leads to transformation of conduct as well as the elimination of error in writings. Since much of Wang's criticism in the Lun-Heng is directed at physical and metaphysical as well as moral writings, we can see this second ability as reaching both moral and nonmoral domains or contexts. Wang also asserts a connection between elimination of false (虛 $x u$ ) writings and moral transformation (we have to assume this is what he means here by 化 hua, as the passage began by speaking of conduct and this should be taken to point back to that). We see again that the ability to discriminate between 實 shi and 虛 $x u$ allows us to both distinguish between 然 ran and 否 fou and to distinguish between 是 shi and 非 fei. In order for this to be the case, there must be some univocal concept of 實 shi that captures the similarities between the various properties which count as $s h i$-properties.

Although it is difficult to completely demonstrate the case based on what Wang says in the Lun-Heng, I suggest that the view I outline below on the univocality of shi is most like the one Wang held. It explains why he didn't see a problem with maintaining its univocality while maintaining pluralism. In addition, the view I attribute to Wang here can, I think, offer us an alternative way to solve some of the problems raised for pluralist theories.

The univocality of shi is based on its second-order status. Shi, for Wang, is the property of having properties that we actually do and should seek when we appraise statements. There are a number of parts of his analysis of shi. First, it is a secondorder property, but a second order pluralistic property. It is not "the property of having some (one) property such that [the truth-making description is met]," (as both Lynch and Wright specify the second-order view ${ }^{35}$ ), but rather it is "the property of having properties such that [the truth-making description is met]." This move actually has a great deal of philosophical payoff, in that it removes the force of objections to pluralism based on the problem of mixed conjunctions, as I explain below.

Shi, for Wang, can be thought of as expressing a second-order property - the property of having a property or properties that we should and do seek when appraising statements. This makes truth rest on normativity. The normativity involved here, however, is basic, in a sense that what we should do is linked with what we do in fact do, but is not explained by the fact that we do these things. That is, the descriptive element is not meant to explain the normative, but be a further basic fact beside it. Here, both concepts are in the employ of the truth function, as an explanation for what makes a particular statement shi. If we consider the properties of 然 ran and 是 shi that can belong to statements in the non-moral and moral domains, respectively, we can begin to see what is meant. The properties of ran and shi are properties humans naturally seek when they appraise sentences, according to Wang. No one accepts as true a statement they believe to be 不然 bu ran or 非 fei. Rather,

\footnotetext{
${ }^{35}$ Although Lynch rejects a second-order property view of truth, in part due to the difficulties discussed below.
} 
the reason a statement is accepted by anyone is because one believes (sometimes mistakenly) that this statement is either 然 ran, 是 shi, or has some other 實 shimaking property. It is a brute fact about humans that we do seek properties such as 是 shi and 然 ran when we appraise sentences and accept or believe statements based on whether or not we have reason to think they are ran or shi. Thus the key question to be answered when we consider whether or not something is 實 shi is whether the statement actually has the properties we naturally seek. In addition to this description of what humans actually do, however, there is an added normative element. Not only do we seek properties like 然 ran and 是 shi, but we ought to seek such properties. Why ought we? That is, what explains the normativity? I believe (though it would take much more space than I have here to argue) that Wang takes this normativity as explanatorily basic. Although this certainly would strike most of us in the contemporary western-based philosophical tradition as strange or implausible, this view (if Wang's own) would not, by any means, have been unprecedented in ancient China. The Mohists give us the best example of a group of thinkers who may have had a similar view of certain normative statements as basic.

Wang's view of the univocality of shi has a couple of interesting features, relevant to the contemporary debate surrounding pluralism and truth in general. It is sometimes objected that pluralism cannot account for the truth of statements or propositions that are conjunctions of propositions belonging to different linguistic domains. The reason for this, in general, is that on most pluralist theories, there are particular properties in particular domains that play the truth role. For example, say that in non-moral contexts, correspondence plays the truth role, while in moral and aesthetic contexts something like coherence plays the truth role. There then becomes a problem in giving an account of what plays the truth role for propositions containing both non-moral and moral or aesthetic conjuncts.

Wang's theory of shi has an easy solution to this problem. In fact, we might think that one of the reasons that the problem never occurred to Wang is that it could never have gained traction given his particular view of shi. Because a statement is shi just in case it has the properties we do and should seek when appraising sentences, it is not necessary for there to be only one particular property playing the truth role for a given statement. The necessity of there being one truth-making property for any given statement or proposition, I contend, is what gets the pluralist into the problem. However, if 'is true' expresses a unique truth property that is linked (in virtue of being a second order property) to the lower level "truth properties", there is no need to rely on only one property to play the truth-making role. Lynch's theory does require a single property to play the truth role for any given proposition, because of his functionalist theory, and Wright appears to need it as well, because he specifies the higher order property as being linked to the (single) property that meets the platitudes in a given domain. The truth property can be defined differently, however, so as not to link it to a single truth-making property that must belong to a statement for it to be true. If a statement is true when it has properties we do and should seek, it is not necessary for a mixed conjunction to have a single lower-level property that 
makes it true. It is enough that both conjuncts are true by virtue of having properties we do and should seek.

Consider the following mixed conjunction:

"Mars is the $4^{\text {th }}$ closest planet to the sun and murder is wrong."

Wang can account for the truth (實 shi) of this statement by analysis of the properties of the logical parts, here the conjuncts. If each of the conjuncts has lowerlevel properties we do and should seek and on the basis of which we do and should accept statements, then the conjunction is 實 shi. And there is no difficulty here, because the two conjuncts are true in exactly the same way-that is, they both possess properties we do and should seek, and thus the entire statement possesses these properties. Note that the entire statement does not possess both ran and shi (the moral conjunct does not possess the property of ran, for example), but the entire statement does possess the second-order property of 實 shi in virtue of the possession of each conjunct of properties we do and should seek. We can explain this ultimately in terms of the properties at the lowest level, in this case 然 ran and 是 shi, but we can construct ever higher levels in the theory of 實 shi. Thus, the above statement is 實 $s h i$ in virtue of having shi-making properties (然 ran and 是 shi), and the conjuncts considered separately are 實 shi in virtue of having 然 ran (in the first conjunct) and 是 $s h i$ (in the second). We can see here that refraining from tying the truth property to a single truth-making lower level property has enormous advantages over the properties defined by Wright and Lynch.

So what of another objection made to the view of the truth property as a secondorder property, which Lynch raises against Wright's second order view of truth? If the second-order property obtains in virtue of a proposition's meeting the various platitudes for truth, then it looks like the truth property itself doesn't meet the platitudes for truth. Thus, the second-order property does not itself qualify as a truth property under the definition of truth properties on Wright's account. ${ }^{36}$ Wang Chong's account of shi does not have this problem. Although it is a second-order property, unlike Wright's truth property it does itself qualify as a truth property under the conceptual description of truth (shi).

The property expressed by shi is the property of (actually) having properties that we do and should seek when appraising statements. Does this property itself meet the

\footnotetext{
${ }^{36}$ Lynch 2009, p. 64-65: "Wright is barred from identifying even this wafer-thin property-the property of having a property that satisfies the platitudes or falls under the concept of truth-with the, or even "a" property of truth. For the property of having a property that falls under the descriptive concept of truth, doesn't itself fall under that description. Again, that description consists, essentially, in a list of the platitudes that a property must satisfy. But is the property of having a property that, e.g., is distinct from warrant, possessed by asserted propositions, is objective, and so on a property with all those features? No. It is the property of having a property with those features. Hence a view like Wright's which identifies truth with whatever property satisfies the platitudes in a particular domain must hold that the second-order property of having a property that plays that role is distinct from truth: call it truth*. And this in turn makes it hard to see how reductive pluralism solves the problem of mixed inferences and associated problems. For while she can say that there is a property preserved by valid mixed inferences, that property is truth*, not truth."
} 
criteria for being shi? That is, is this property something that we do and should seek when appraising statements? It is. But notice that we will only be concerned about whether or not shi obtains when there is semantic ascent, or some question as to whether a certain statement does actually or does not have the lower-level properties we seek when appraising statements. Consider the statement:

"One should imitate the actions of the Zhou kings."

This statement may be 實 shi by virtue of having the property of 是 shi (right). So there are two relevant properties here一實 $s h i$ (true) and 是 $s h i$ (right). 實 Shi is the second order property. So, are we looking for that when we appraise this sentence? In a sense we are-we are looking for both. The second order property is especially relevant when we engage in semantic ascent. Consider the statement:

“The statement 'you should imitate the actions of the Zhou kings' is true (實 shi)."

What property or properties do we and should we seek when appraising this sentence? Now that we have semantically ascended, the lowest level properties such as 然 ran and 是 shi will be out of the immediate picture, and the sentence must be appraised to see if it has the property of 實 shi. What we ought to and will seek here is the second order property itself, because the possession of this will tell us whether the relevant statement is true. Thus, the relevant properties of this statement are the original property of 是 $s h i$ (right), which makes the second order property of 實 $s h i$ obtain, and a third-order 實 shi property along side of that.

So the question of whether the second (and higher) order property of shi can be something itself that counts as a truth property under the given definition of truth can be answered in the affirmative. ${ }^{37}$ The definition of truth given here does not bar

\footnotetext{
${ }^{37}$ There may be some worry here that the property of 實 shi belonging to mixed conjunctions (preascent) will be third-order properties rather than second-order properties. If we take the shi-ness of the full conjunction as a function of the shi-ness of the conjuncts, this will necessarily be the case. However, I do not believe this is the right way to see shi in cases of conjunctions, or any statement. What I propose here goes beyond anything Wang says, of course, and is meant as simply a way of making sense of how shi is a second-order property even in cases of mixed conjunctions. Since shi is an appraisal term - it is a property that belongs to a statement if and only if that statement has the properties we do and should seek in appraising statements - it need only apply to appraised statements. That is, shi might be understood as a tag telling us whether a statement has the desired properties or not. It need not be the case, if we are appraising a conjunction, that the conjunction is shi based on each of the conjuncts being shi, even if those conjuncts would be shi if appraised individually. The reason shi can work like this is that it is based on human goals - what we do and ought to seek. Thus, independently of our appraisal of a particular statement, there do not have to be shi-facts about it. Thus, a mixed conjunction can have the second-order property of shi based on having the property of ran and shi in its conjuncts, without being based on having the individual property shi of each conjunct. However, if we appraise the conjuncts separately as individual statements, we can also take them as having the property of $s h i$, based on the lower-level properties each possess. As I say above, this explanation goes well beyond anything we can find in Wang Chong, but I believe this addition keeps with Wang's general view of shi, and gives us a way to better understand how a shi property like Wang's can work.
} 
higher-order properties constructed in this way from serving as truth-making properties.

So we have seen that Wang can offer us a way of understanding how the predicate 'is true' can express a unique, second-order property, while avoiding some problems for such views. Of course, accepting something like Wang's view depends on how far we're willing to go with him on the explanatory basic quality of descriptive and normative facts about human behavior. We might part ways with Wang at a number of different points - whether it has to do with our objection to holding truth to be that closely linked with human behavior (is this a radical anti-realism?), whether it has to do with our resistance to accepting as basic the kinds of facts Wang does, or whether it has to do with issues of possible vicious circularity in the definition of 實 shi. All of these issues, of course, remain to be worked out. But if they can be satisfactorily worked out, we have a ready made way to answer objections to pluralist theories of truth as well as a way to offer better explanations for certain key features of truth that any theory, pluralist or monist, must account for.

In addition to helping in the contemporary debate surrounding truth and pluralism, Wang's pluralist view of shi, focusing as it does on the distinction between moral and non-moral statements, also might help us to understand the concept of truth in early Chinese philosophy in general. Although the particular formulation of a pluralist theory of truth using shi as the truth concept is new to Wang, implicitly pluralist theories of truth in China in general do not begin with Wang Chong. Pluralist intuitions about truth can be found as early as the $M o-Z i$. The best way to understand the seeming switch between pragmatic-sounding arguments and correspondence based reasoning in the $\mathrm{Mo}-\mathrm{Zi}$ can be explained by attributing a pluralist conception of truth to the author(s) of the text. This conception is not fleshed out in early texts such as the $M o-Z i$, however. I also suspect that this incipient pluralism about truth is at the heart of the "paradoxes" of the Gong-Sun-Long-Zi. Gong Sun Long is, I believe, noticing an intuitive difficulty with pluralist theories of truth that arises when we have defined no univocal concept of truth that captures the different truth-making properties. With Wang's more worked out (although not fully worked out) conception of shi as truth, we can look backward to come to a better understanding of the incipient pluralism in earlier thinkers. In this sense, understanding Wang's theory of shi can help us to understand truth in early China in general. Of course, the tie between Wang's theory and those of his predecessors will have to be developed in future work.

\section{ACKNOWLEDGEMENTS}

An earlier version of this paper was presented at the Midwest Conference for Asian Affairs 2009 at Miami University, Oxford, OH. I would like to thank those who attended for their insightful questions and comments. I would also like to thank three anonymous reviewers from Comparative Philosophy whose valuable comments helped clarify and strengthen my arguments in this paper. 


\section{REFERENCES}

Forke, Alfred (1907), Lun-heng: Philosophical Essays of Wang Ch'ung (Georg Reimer)

Gupta, Anil (1993), “A Critique of Deflationism”, Philosophical Topics 21: 57-81.

Hall, David \& Roger Ames (1998), Thinking From the Han (Albany, N. Y.: State University of New York Press).

Hansen, Chad (2000), A Daoist Theory of Chinese Thought (New York: Oxford University Press).

Lynch, Michael (2001), "A Functionalist Theory of Truth”, in Michael Lynch (ed.) The Nature of Truth (Cambridge, Mass.: MIT Press).

---- (2009), Truth as One and Many (New York: Oxford University Press).

Makeham, John (1994), Name and Actuality in Early Chinese Thought (Albany, N.Y.: State University of New York Press).

McLeod, Alexus (2007), “A Reappraisal of Wang Chong's Critical Method Through the Wenkong Chapter of the Lun-Heng", Journal of Chinese Philosophy 34.4: 581-96

Mou, Bo (2006), “Truth Pursuit and Dao Pursuit: From Davidson's Approach to Classical Daoist Approach in View of the Thesis of Truth as Strategic Normative Goal", in Bo Mou (ed.), Davidson's Philosophy and Chinese Philosophy: Constructive Engagement (Leiden: Brill), 309-49.

----(2009), Substantive Perspectivism: An Essay on Philosophical Concern with Truth (Dordrecht: Springer).

Nylan, Michael (1996), "Han Classicists Writing in Dialogue About Their Own Tradition", Philosophy East and West 47.2

Puett, Michael (2001), The Ambivalence of Creation: Debates Concerning Innovation and Artifice in Early China (Stanford: Stanford University Press).

Siderits, Mark (2003), Personal Identity and Buddhist Philosophy: Empty Persons (Ashgate).

Van Norden, Bryan W (2007), Virtue Ethics and Consequentialism in Early Chinese Philosophy (New York: Cambridge University Press).

Wang Chong (1996), Lun-Heng-Zhu-Zi-Suo-Yin《論衡逐字索引》[Critical Essay: Concordance], D. C. Lau (ed.), Chinese University of Hong Kong Institute of Chinese Studies, Ancient Text Concordance Series, No. 22 (Hong Kong: The Commercial Press).

Wright, Crispin (1992), Truth and Objectivity (Cambridge, Mass.: Harvard University Press).

---- (2001), "Minimalism, Deflationism, Pragmatism, Pluralism", in Michael Lynch (ed.), The Nature of Truth (Cambridge, Mass.: MIT Press). 